NASA Technical Memorandum 106060

AIAA-92-3213

\title{
Space Transfer With Ground-Based Laser/Electric Propulsion
}

Geoffrey A. Landis, Mark Stavnes and Steve Oleson Sverdrup Technology, Inc.

Lewis Research Center Group

Brook Park, Ohio

and

John Bozek

National Aeronautics and Space Administration

Lewis Research Center

Cleveland, Ohio

Prepared for the

28th Joint Propulsion Conference and Exhibit cosponsored by the AIAA, SAE, ASME, and ASEE

Nashville, Tennessee, July 6-8, 1992 


\title{
SPACE TRANSFER WITH GROUND-BASED LASER / ELECTRIC PROPULSION
}

\author{
Geoffrey A. Landis, Mark Stavnes, and Steve Oleson \\ Sverdrup Technology, Inc., \\ NASA Lewis Research Center 302-1 \\ Cleveland, OH 44135 \\ John Bozek \\ NASA Lewis Research Center 301-5 \\ Cleveland, $\mathrm{OH} 44135$
}

\begin{abstract}
A new method for providing power to space vehicles consists of using ground-based lasers to beam power to photovoltaic receivers in space. This can be used as a power source for electrically propelled orbital transfer vehicles.
\end{abstract}

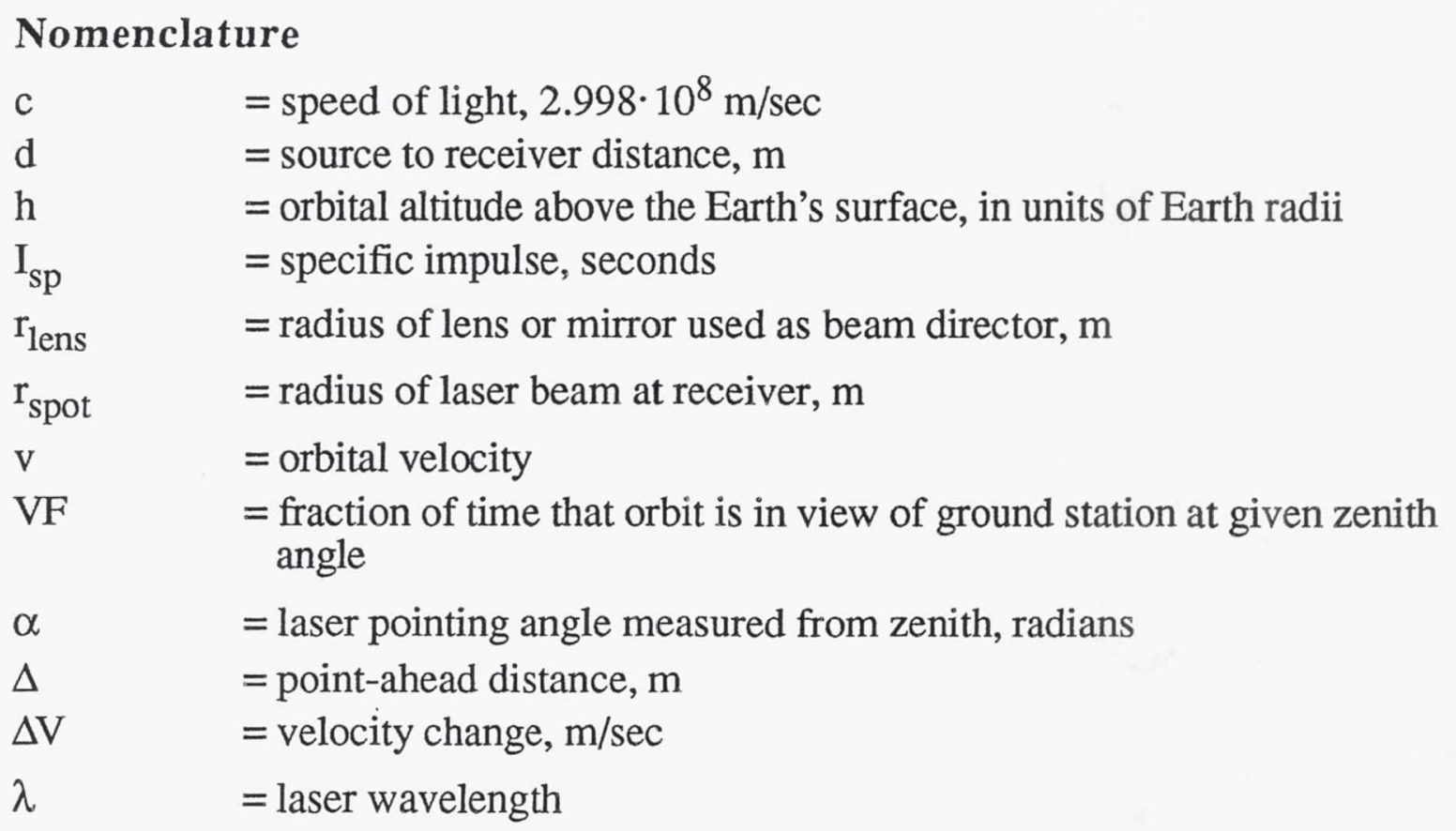

Paper AIAA-92-3213, presented at the AIAA/SAE/ASME/ASEE 28th Joint Propulsion Conference, July 6-8 1992, Nashville, TN. 


\section{Introduction}

While the use of lasers to transmit power to photovoltaic arrays was proposed by Backus in 1972 [1], except for a few proposed applications using space-based lasers [2], few applications of this concept were proposed until recently. However, technological advances over the last few years in high-power lasers and adaptive optics have made such concepts more realistic [3].

In this paper, we will discuss use of a ground-based laser to beam power to a photovoltaic array on an orbital transfer vehicle (OTV) as a method of providing power for an electric-propulsion system. We will compare three power systems: the case where the photovoltaic array is illuminated only by the laser ("laser-electric propulsion"), the case where the photovoltaic array is illuminated only by the sun ("solar-electric propulsion"), and the case where the photovoltaic array is illuminated by the laser when the vehicle is in view of the laser ground station and by the sun when it is not.

Producing power for an OTV by illuminating photovoltaic arrays with a ground-based laser has several advantages over chemical and solar-electric propulsion [3]. Solar cells are more efficient under monochromatic illumination than under the wide spectral range of solar illumination [4-6]. In addition, the intensity of a laser source can be increased to provide higher power output per unit of array area. Finally, a laser source allows the possibility of thermal annealing of radiation damage of photovoltaic arrays, which may allow longer lifetimes and higher efficiencies for power systems orbiting in or near the radiation belts.

The ground-based laser system $[7,8]$ is made up of one or more high average-power lasers situated, whenever possible, at low cloud coverage sites such as mountaintops. To reduce the beam spread due to diffraction, the optical element (telescope) of the system must have a large effective aperture. Additionally, adaptive-optics are required to compensate for the distortions in the beam due to the turbulence of the atmosphere. Finally, the laser system must be able to track the transfer vehicle in orbit when it is in view of the laser site.

Electric propulsion technologies such as ion engines [9], thermal engines, or electromagnetic thrusters [10] can have extremely an high specific impulse, from several hundred to 10000 seconds [11] (compared to $\sim 400$ for space-storable chemical fuels). Hence, electric propulsion offers the possibility of dramatically reducing the reaction mass required to be launched into low Earth orbit, and thus decreasing the cost of in-space transportation for missions such as orbital transfer or lunar base support. However, electric propulsion systems have extremely high power requirements, especially for high thrust and high specific impulse systems. Thus, a laser-based power system that increases the power available to an electric propulsion system could significantly enhance the performance of electrical orbital transfer vehicles.

A laser-electric orbital transfer vehicle could have useful applications for many missions, including raising satellites from low Earth orbit (LEO) into the commercially valuable geosynchronous Earth orbit (GEO), orbit raising and plane changes in other orbits, station-keeping, and ferrying cargo from LEO into lunar orbit for construction and resupply of a lunar base. In this discussion we will focus primarily on the LEO to GEO transfer vehicle, while recognizing that other applications may be equally important

Compared to a space-based laser, use of a ground-based laser simplifies maintenance and heat-rejection, and allows the laser to be designed with relaxed requirements for low mass, high reliability, and high efficiency, since power is available on Earth at an effective cost roughly a thousand times less than the cost in orbit. 
The system discussed relies on five key technologies:

(1) High-power lasers

(2) Large aperture optical elements

(3) Adaptive optics

(4) Photovoltaic receivers

(5) Electric propulsion

The feasibility of such a power system relies on recent technological advances in all of these key technologies.

\section{HIGH-POWER LASERS}

Lasers to be considered must operate in the wavelength range centered around the visible spectrum in which the atmosphere is nearly transparent. The minimum wavelength is about $350 \mathrm{~nm}$, limited by the atmospheric absorption (primarily ozone) and Raleigh scattering [12]. Atmospheric turbulence correction is easiest at longer wavelengths, since the turbulence coherence length increases with wavelength. The maximum wavelength is limited to about $1100 \mathrm{~nm}$ for existing photovoltaic technology.

Several types of lasers are possible for the power source [13]. Free-electron lasers (FELs) offer the possibility of megawatt and higher power levels in a single unit, with the possibility of tuning the wavelength of operation to an optimum value for atmospheric transparency and solar cell efficiency. A high power free electron laser operating at ten microns is currently under construction; this laser is capable of being adapted to operation in the desired range of about $850 \mathrm{~nm}$, where typical photovoltaic cells operate. A FEL will inherently be pulsed, with the output consisting of a continuous string of pulses with high peak power.

Alternatively, the semiconductor diode laser $[13,14]$ also operates at high efficiency in the wavelength range of $800-840 \mathrm{~nm}$, which is well suited for photovoltaic receivers. Semiconductor diode laser arrays of about 100 watts average power have been constructed, and research is continuing into higher power levels. For a system to have high enough power to be useful for electric propulsion systems, many such diode arrays would be operated in phase to provide the power levels needed.

\section{LARGE APERTURE OPTICAL ELEMENTS}

The minimum spot radius of a transmitted laser beam is set by the diffraction limit,

$$
\mathrm{r}_{\text {spot }}=0.61 \mathrm{~d} \lambda / \mathrm{r}_{\text {lens }}
$$

The defined spot radius contains $84 \%$ of the beam energy. Hence, to make a spot size comparable to a solar array size at orbital or lunar distances, large optical elements are needed.

Recently a wide variety of new technologies for manufacturing large telescope mirrors have been developed [15], and it is reasonable to project that mirrors of a scale of tenmeter diameter, or even larger, may be available for laser use. Mirrors such as the $10-\mathrm{m}$ diameter Keck telescope are currently being produced by use of segmented optics. In this approach, many smaller mirrors are put together into a single large optical element. At the distance of geosynchronous orbit (GEO), this mirror would allow a diffraction-limited spot of about 5 meters diameter. At the distance of the moon, the diffraction-limited spot would be about 80 meters in diameter. The smaller spot size at GEO compared to lunar orbit means that smaller systems are feasible for a LEO-GEO transfer vehicle than for lunar shuttle applications.) 


\section{ADAPTIVE OPTICS}

A diffraction-limited spot can only be achieved if adaptive optics are used to eliminate atmospheric beam spread. In the real world, pointing accuracy and atmospheric turbulence will degrade the laser spot size. Achievable pointing accuracy is high enough that this is not a limiting factor. Atmospheric turbulence limits the resolution limit of astronomical telescopes to slightly less than 1 second of arc, or about 4 microradians, increasing slightly at shorter wavelengths. At the distance of GEO, $3.5 \cdot 10^{7} \mathrm{~m}$, this contributes about $135 \mathrm{~m}$ to the spot diameter. Such a large beam spread is not acceptable.

Adaptive optical techniques [16] must be used to reduce the beam divergence and jitter spread due to atmospheric turbulence. As a result of developments in astronomy and in defense laser applications, adaptive optics have been developed which allow atmospheric turbulence to be removed to near diffraction-limited capability. In general, this requires a light source from the spacecraft ("beacon") to sample the atmosphere along the laser path. The distortion in the beacon signal is then reversed to compensate the upward traveling power beam. This is possible because the time scale for atmospheric turbulence is much longer than the travel time for a light beam to traverse the atmosphere.

Ideally, the beacon is a laser on (or in the same orbit as) the spacecraft. This laser need only have a power of roughly a watt. Optimum atmospheric compensation requires that the beacon be ahead of the receiving array by a distance equal to the travel time of the beam times the orbital velocity. For a vehicle directly over the laser station, the pointahead distance $\Delta$ is

$$
\Delta=2 \mathrm{vd} / \mathrm{c}
$$

This assures that the returning power beam will be aimed at the spot where the receiving array will be after a round-trip travel time, and hence that the atmospheric path for the downward-directed beacon is the same as that of the upward-directed power beam. This point-ahead distance is about 730 meters in geosynchronous orbit. If the beacon laser is at the receiving array location, rather in the point-ahead position, the atmospheric compensation will be degraded, since the downward atmospheric path sampled will be slightly different than the upward path taken by the power beam.

Alternatively, it is possible to sample the atmosphere without having a physical beacon attached to the spacecraft. A light source at an altitude of $\sim 90 \mathrm{~km}$ can be synthesized by illuminating the sodium region in the ionosphere with a ground-based laser $[17,18]$; this signal can then be used to sample the atmosphere. This has the advantage of allowing point-ahead without requiring a long boom or a co-orbiting beacon. The difference in altitude between the beacon and the spacecraft adds a slight source of error ("anisoplanatic error"); which can be reduced somewhat by using more than one beacon.

The adaptive optical component works by adjusting the surface of an optical element to exactly reverse the phase distortion of the downward sampled light; thus the sum of the phase distortion from the mirror and the atmosphere on the upward traveling laser light cancels to zero, and the beam is planar on leaving the atmosphere. This reverse distortion is done by means of a large number of individual mirror elements, each adjusted continuously by computer according to the sampling of the atmosphere. The adjustable elements may be either in the primary mirror [19], or small elements in a secondary mirror.

The ability to compensate atmospheric turbulence rapidly degrades as the path length through the atmosphere increases, and it is likely that the maximum angle from zenith for which the system can be used will be in the range of $45^{\circ}$ to $60^{\circ}$.

Due to the smaller atmospheric turbulence scale size at shorter wavelengths, adaptive optics considerations suggest that the longer the wavelength, the better the atmospheric 
compensation will be. Diffraction considerations, however, suggest that the wavelength should be as short as possible. As a result the wavelength of operation is likely to be a compromise with the performance of the solar cell, in the range of $800-1100 \mathrm{~nm}$.

Some additional defocusing effects such as thermal blooming and phase-conjugate distortion are encountered by beams at high intensities. The power levels discussed here, however, are at low enough intensities that these effects can be compensated by the adaptive system.

\section{PHOTOVOLTAIC RECEIVERS}

Existing photovoltaic cells have demonstrated efficiencies of over $50 \%$ for conversion of CW laser radiation at the appropriate wavelength to electrical energy. A more detailed discussion of the issues involved in selecting solar cells for use as laser power converters can be found in references [4-6]; this discussion here will only briefly introduce the issues involved.

Existing solar cells have peak response to monochromatic illumination between about $850 \mathrm{~nm}$ (for GaAs cells) and about $950 \mathrm{~nm}$ (for Si cells), as shown in figure 1 [4,20]. Silicon cells with extended long-wavelength response have been made with the peak response as long as $1030 \mathrm{~nm}$ and significant response even at $1060 \mathrm{~nm}$, but these cells have not yet been designed with high radiation tolerance, and may not be usable for beltcrossing orbits which encounter radiation. For wavelength shorter than the peak, the efficiency decreases roughly linearly with wavelength; for longer wavelengths, the efficiency drops to zero. High efficiency GaAs cells produce roughly $50 \%$ efficiency under laser illumination; conventional Si cells about 40\%, and Si cells with extended longwavelength response about $45 \%$.

There is some interest in using lasers of longer wavelengths. There is another atmospheric window in the range of 1.5 to $1.7 \mu$-m; use of wavelengths in this range have been suggested due to the availability of high-power chemical lasers and the "eye-safe" operation. For such wavelengths, it would be necessary to develop new solar cell materials, using germanium, GaSb, or III-V ternary or quaternary compounds such as InGaAs, with response at the appropriate wavelength. In general, the efficiency will decrease as the wavelength of peak response increases, as indicated in figure 1.

Solar cell operating temperature can be an important consideration for many applications, and puts a limit on the highest intensities possible. The efficiency of a solar cell will decrease with operating temperature. The efficiency degradation is expressed by the temperature coefficient. This is lowest (i.e., least sensitive to temperature) for widebandgap (short wavelength) cells such as GaAs, and increases for narrow-bandgap (long wavelength) cells such as $\mathrm{GaSb}$ and $\mathrm{Ge}$.

For an orbital transfer vehicle power system, it is important to be able to put high laser power on the array in order to maximize the power output. Because of the decreasing efficiency with temperature, there is a maximum input power, above which the power output of the cell actually decreases as the incident power increases [5]. This results in a maximum output power, for a GaAs cell operated at high temperature, of roughly ten times the output of a similar array operating under solar illumination. This is shown in figure 2, which shows a preliminary calculation of the output of a GaAs photovoltaic array with an efficiency of $54 \%$ under laser illumination at $28^{\circ} \mathrm{C}$. The array is assumed to be in low Earth orbit. More exact calculations of the power output will be presented later [21].

If the solar array is to be operated at this maximum power output, solar cell degradation due to high temperature operation must be addressed. Conventional solar cells are not designed to operate at temperatures above about $100^{\circ} \mathrm{C}$, however, advanced solar cells 
specifically designed to avoid thermal degradation can withstand significantly higher temperatures [22]. It will also be necessary to chose a coverglass bonding method which is not susceptible to thermal damage, such as electrostatic bonding [23] or hightemperature adhesive.

The radiation levels in space can be an important factor, especially for transfer orbits between low earth orbit (LEO) and geosynchronous orbit (GEO). An additional advantage of using laser illumination is that at high intensities, the laser may thermally anneal the radiation damage. While, in general, high operating temperatures decrease cell efficiency, operating at high temperatures may result in radiation damage being annealed out continuously during flight, effectively eliminating this source of degradation. This would result in significant increases in the array performance for missions that must operate in the Van Allen radiation belts, such as a LEO-GEO orbital transfer vehicle.

Some lasers, such as a free electron laser, inherently run in a pulsed mode, where the pulses may be very short and the pulse rate high enough that sufficient average power is achieved. For this mode of operation, the peak power may be much higher than the average power. Since thermal time constants are much longer than typical time between pulses for FEL systems, the thermal response of cell is to laser average power. However, since for many types of cells the cell electrical response time will be shorter than the pulse spacing, the cell electrical output will track the laser peak power. Thus, the cell must be designed to minimize series resistance. Additional effects involve the interaction of the short pulse with the inductance and capacitance of the cell. [5]. The effects of pulsed illumination on solar cells are not well understood, and are currently under study.

\section{ELECTRIC PROPULSION}

Electric propulsion technologies have recently moved from the regime of experimental tests to that of working devices on spacecraft [11]. There are a wide variety of welldeveloped technologies, including resistojets, arc-jets, magnetoplasmadynamic thrusters, ion engines, and advanced technology concepts [24]. These are characterized by higher specific impulse than chemical systems. High specific impulse and low propellant usage leads to high payload fraction, however, high specific impulse systems are inherently energy inefficient, and require extremely high power to reach high thrust levels. Lower specific impulse systems such as plasma thrusters have higher thrust, and hence typically allow shorter trip times at the expense of more propellant used. Even lower specific impulse thrusters such as the resistojet can be used to produce higher thrust. It is thus necessary to trade off specific impulse (propellant efficiency) with energy efficiency.

\section{Laser-Electric OTV System Analysis}

To investigate the benefits of laser power beaming to an orbital transfer vehicle, a mission analysis was conducted to compare the trip times for a hypothetical electric propulsion OTV designed to raise a $2500 \mathrm{~kg}$ payload from LEO to GEO. Three photovoltaic power systems were compared: (1) PV arrays illuminated only by the sun, (2) PV arrays illuminated by ground-based laser, only during the portion of the orbit in view of the laser ground station), and (3) PV arrays illuminated by ground-based laser during the portion of the orbit in view of the laser ground station, and by sunlight at other times.

The performance of a laser-powered electric propulsion OTV is dependent on the assumptions made of vehicle system mass.

This analysis assumed a simple, reusable orbital transfer vehicle. The vehicle was assumed to break down into five subsystems: power system, propulsion system, 
propellant and tanks, payload, and structure and support systems. The power system consists of the photovoltaic array and a power management and distribution system. Propellant tanks were assumed to be $12 \%$ of the propellant mass. The vehicle structure and support systems were modeled on the Mariner Mark II bus. The mass of the beacon laser, if required, was assumed to be negligible. A mass contingency of $30 \%$ was assumed for all elements except for the propellant and payload; this accounts for the normal increase in vehicle mass from initial design to launch.

Table 1 śhows a typical mass breakdown of the vehicle, in this case for the LEP vehicle optimized for a $500 \mathrm{~km}$ starting orbit.

The performance will depend on the view factor, that is, the fraction of time that a ground station can beam power to a given orbital altitude. This depends on the maximum angle $\alpha$ from the vertical that the laser station can point (due to increasing atmospheric path turbulence at high angles). The likely maximum zenith angle $\alpha$ will be in the range of $45-70^{\circ}$, depending on the optics; $60^{\circ}$ was assumed here. For the best case, where the vehicle is in equatorial orbit and the ground stations are on the equator, the view factor is:

$$
\mathrm{VF}=\alpha / \pi-1 / \pi \sin ^{-1}[\sin \alpha /(1+\mathrm{h})]
$$

This is shown in figure 3 . The view factor decreases to zero extremely rapidly at low altitudes. Thus, for maximum utilization of the laser, it is important that the orbital altitude be as high as possible as quickly as possible.

Higher viewing times can be obtained by multiplying the number of ground stations, or by using a relay mirror in Earth orbit to redirect the beam. For the calculations here we assumed four ground stations, located at Alice Springs in Central Australia, Johnston Island in Micronesia, White Sands Missile Range in the United States, and Central Morocco in north Africa. The sites were selected for low average cloud coverage, and viewing times do not include the effect of obscuration by clouds. Orbit illumination fractions as a function of altitude for these sites were obtained from Gordon Woodcock (Boeing Civil Space Systems, reference [25]). These illumination factors included the plane change from an initially $28.5^{\circ}$ orbit to the equatorial geosynchronous orbit, and also accounted for the overlap in coverage when the altitude increases.

Since the viewing times of the orbit increase rapidly as the initial orbital altitude increases, by using the chemical booster to place the OTV in a higher starting orbit, a great reduction in trip time is possible. We looked at the performance as a function of the initial orbital altitude.

We assumed that when the spacecraft was in view of the laser stations within the acceptable viewing angle, the laser stations could produce as much power to the spacecraft as the arrays could accept. The solar array was assumed to use high-efficiency GaAs cells that are capable of converting both solar and laser illumination. As shown in Figure 2, the laser-illuminated array produces ten times the power per unit area as the array under solar illumination, including the effect both of higher efficiency and of higher intensity. In addition, the laser illuminated array was assumed to continuously anneal the radiation damage during passage through the Van-Allen radiation belts due to the high operating temperatures. The solar array requires shielding from the radiation, provided by a glass cover on the front of the cell and by the array structure on the back. The reduced requirement for shielding mass improves the specific power of the laser array by an additional $37 \%$ compared to the solar array. The total power system mass is shown in table 2. The laser was assumed to have sufficient power to fully illuminate the array, and thus it was unnecessary to calculate Strehl and beam atmospheric absorption.

Using the illumination fraction as a function of nearly circular orbit altitudes and the estimated low thrust $\Delta \mathrm{V}[26]$, the trajectory was integrated piecewise until 
geosynchronous orbital altitude with $0^{\circ}$ inclination was reached. Earth power station elevation restrictions are considered, however, when calculating orbit illumination fraction. We compared three systems; laser power alone; solar power alone; and the case where laser power is used when the spacecraft is in range of a laser station, and solar power is used when the spacecraft is not in view but is in sunlight. This allows the OTV to raise in altitude more quickly and, consequently, receive more laser illumination.

Lower trip time can be obtained at a cost of decreased payload. For the comparison between laser and solar powered OTVs, we assumed a $2500 \mathrm{~kg}$ payload for both systems. For comparison, an Atlas II launch vehicle can lift a mass of $8400 \mathrm{~kg}$ to parking orbit of $80 \times 279$ nautical miles $\left(28.5^{\circ}\right)$, and can deliver $2700 \mathrm{~kg}$ to geostationary orbit.

Table 3 shows the specific mass assumptions of the power and propulsion system for laser- and solar-powered OTVs. The propulsion system was assumed to use an advanced electrodeless pulsed inductive thruster [24] with a specific impulse of 5000 seconds and efficiency of $50 \%$, which has been demonstrated (at the single-pulse level) in laboratory experiments [24]. A specific mass of $0.5 \mathrm{~kg} / \mathrm{kW}$, somewhat lower than that achieved with currently demonstrated thrusters, was assumed. For comparison, performance parameters of several available types of electric engines, including ion, arcjet and typical magnetoplasmadynamic thrusters are shown in table 3. A specific impulse of 5000 seconds was chosen as a compromise between payload fraction and power. It is likely that this $I_{s p}$ is higher than the optimum, and that by increasing the thrust, a lower $I_{s p}$ would increase performance. No attempt has been made to search the parameter space for optimum performance.

It has also been pointed out that using a flight profile with low $\mathrm{I}_{\mathrm{Sp}}$ and high thrust at the beginning of the orbit raising, and then increasing $\mathrm{I}_{\mathrm{Sp}}$ and decreasing thrust later in the flight, could result in considerable performance improvement by quickly raising the orbit (and hence increasing the laser view factor) away from the initial low orbit with correspondingly low view factor.

The orbital transfer vehicle was assumed to be reusable. The mission chosen, $2500 \mathrm{~kg}$ to GEO, was sized as a typical commercial payload. The OTV power system was sized approximately to an Atlas launch, resulting in a power of $250 \mathrm{~kW}$ for the SEP and 1000 $\mathrm{kW}$ for the LEP vehicle.

Figure 4 shows the initial mass required in low Earth orbit as a function of the initial altitude, both for the initial vehicle launch and the subsequent trip (resupply) launches. There is no significant difference in mass between the laser- and the solar-electric vehicles. Also shown are the launch capabilities of the Atlas and Delta launch vehicles. For the orbital altitudes of 500 and $1000 \mathrm{~km}$, the subsequent trips can be launched on a Delta. Initial altitudes above $1000 \mathrm{~km}$ are out of the Delta range.

Figure 5 shows trip times as a function of the initial altitude (broken down into outbound and return portions). Since $1000 \mathrm{~km}$ is the highest initial altitude that can be reached with the Delta at the payload required, this is the best value for comparison between the three cases.

It is evident that the out-bound trip times for a LEP OTV vary (as a function of initial altitude and whether or not solar augmentation is used) from a low of 1 month to a high of 3 months. From the $1000 \mathrm{~km}$ initial orbit, the SEP OTV requires four months to reach GEO; the laser OTV without solar reduces this to slightly over two months, and the solar augmentation decreases it yet further, to about 52 days.

The real advantage of using a tug system is to deliver many payloads to a desired orbit with a reusable stage. After the vehicle is in operation, a Delta launch vehicle can be used to launch the next satellite and resupply propellant to the OTV. Since direct launch to GEO 
of $2500 \mathrm{~kg}$ requires an Atlas launch, the reusable electric propulsion OTV allows the change from an Atlas to a Delta. Use of a Delta rather than an Atlas represents a savings in launch cost of roughly 75 million dollars per flight for the electric propulsion system compared to chemical boosters.

These performance numbers should be taken as indicative of performance trends, not be taken as accurate engineering models. Performance depends critically on the assumed power and propulsion figures of merit shown in table 2. In particular, the PMAD (power management and distribution) system is a major component in the mass of the vehicle. Since wiring is a major component of this mass, the smaller arrays allowed by laser power could decrease PMAD mass considerably; this issue needs to be studied. The effect of a pulsed laser input on array and PMAD efficiency likewise needs to be studied.

The specific impulse used, 5000 seconds, was not optimized, and choosing a specific impulse to optimize the parameters of importance may considerably increase the performance of the system. Further optimization and trade-off studies are underway, and will result in a more clear understanding of the important factors in the performance and a better estimate of the possible gains to be obtained by laser-electric propulsion.

\section{Conclusions}

Technology advances in lasers and adaptive optics make ground-to-space power beaming an attractive new option for high-power requirements in near-Earth space. Laser power beaming offers the potential for increasing the power density available on photovoltaic power systems in space, and hence improving the performance of orbital transfer vehicles using electric-propulsion. An calculation of the performance of a sample laser-electric OTV shows that laser-electric propulsion can lower the class of launch vehicle required for launching a $2500 \mathrm{~kg}$ satellite to GEO from an Atlas to a Delta compared to a chemical transfer stages, and decrease the required trip time by a factor of two over a solar electric OTV.

\section{Acknowledgements}

Since the SELENE project started a year ago, a great number of people have began to study the issues involved in laser power beaming from the surface of the Earth, and we have been fortunate in having access to discussions of many of the issues involved in workshop meetings and various preprints. Valuable contributions have been made by individuals at MIT Lincoln Labs, Science Applications International, JPL, Marshall Spaceflight Center, W.J. Schaffer, and Science Research Laboratories. Most of this research is as-yet unpublished, or published only in workshop documents not publicly available [27]; it is to be hoped that it will appear in the open literature swiftly!

The authors would like to acknowledge the work done on this and similar power systems by many co-workers, including similar concepts proposed independently by John D. Rather at NASA Headquarters, concepts for space-based laser systems proposed by Judith Bamberger and Ed Coomes at Pacific Northwest Laboratories, early analysis of the concept by Julio Acevedo and Jose Christian at NASA Lewis, and experimental investigations of solar cell performance under laser illumination by co-workers including Phil Jenkins, Roland Lowe, and Bruce Anspaugh.

This work has been supported by NASA Lewis Research Center under contract NAS325266. 


\section{References}

1. C.E. Backus, "Laser Activation of Solar Cells," Proc. 9th IEEE Photovoltaic Specialists Conf., Silver Spring, MD, May 1972, pp. 61-65.

2. R. J. DeYoung, ed., Second Beamed Power Workshop, NASA Conference Publication 3037, NASA Langley Research Center, Hampton, VA Feb. 28-Mar. 2, 1989.

3. G.A. Landis, "Space Power by Ground-Based Laser Illumination," IEEE Aerospace and Electronic Systems, Vo. 6, No. 6, pp. 3-8 (1991); presented at 26th Intersociety Energy Conversion Engineering Conference, Aug. 1991, Boston, MA.

4. P.A. Iles, "Non-Solar Photovoltaic Cells," Proc. 21st IEEE Photovoltaic Specialists Conf., Vol. 1, Kissimimee, FL, May 1990, pp. 420-425.

5. G.A. Landis, "Photovoltaic Applications for Beamed Power in Space," Proc. 22nd IEEE Photovoltaic Specialists Conf., Vol. 2, Las Vegas, NV, Oct. 1991, pp. 14941502; available as NASA Tech. Memo. 105325 (1991).

6. L.C. Olsen, D.A. Huber, G. Dunham, F.W. Addis and N. Anheier, "HighEfficiency Monochromatic GaAs Solar Cells," Proc. 22nd IEEE Photovoltaic Specialists Conf., Vol. 2, Las Vegas, NV, Oct. 1991, pp. 419-423.

7. G.A. Landis, "Satellite Eclipse Power by Laser Illumination," International Astronautics Federation paper IAF-90-053; Acta Astronautica, Vol. 25, No. 4, 229233 (1991).

8. G.A. Landis, "Moonbase Night Power by Laser Illumination," J. Propulsion and Power, Vol. 8, No. 1, pp. 251-254 (1992).

9. E. Stuhlinger, Ion Propulsion for Space Flight, McGraw-Hill, NY (1964).

10. R.G. Jahn, Physics of Electric Propulsion, McGraw-Hill, NY (1968).

11. F.M. Curran, J.S. Sovey and R.M. Myers, "Electric Propulsion: An Evolutionary Technology", paper IAF-91-241 (1991).

12. H. Weichel, Laser Beam Propagation in the Atmosphere, SPIE Optical Engineering Press, Volume TT-3, Bellingham, WA (1990).

13. R.J. De Young, J.H. Lee, M.D. Williams, G. Schuster, and E.J. Conway, Comparison of Electrically Driven Lasers for Space Power Transmission, NASA Technical Memorandum 4045, 1988.

14. M.D. Williams, J.H. Kwon, G.H. Walker, and D.H. Humes, "Diode Laser Satellite Systems for Beamed Power Transmission," NASA Technical Paper 2992, July 1990.

15. C.S. Powell, "Mirroring the Cosmos," Scientific American, Nov. 1991, pp. 113123.

16. C.A. Beiochman and S. Ridgway, "Adaptive Optics and Interferometry," Physics Today, Apr. 1991, 48-51.

17. C.A. Primmerman, D.G. Murphy, D.A. Page, B.G. Zollars and H.T. Barclay, "Compensation of Atmospheric Optical Distortion Using a Synthetic Beacon," Nature 353, pp. 141-144 (1991).

18. R.Q. Fugate, D.L. Fried, G.A. Ameer, B.R. Boeke, S.L. Browne, P.H. Roberts, R.E. Ruane, G.A. Tyler and L.M. Wopat, "Measurement of Atmospheric Optical Distortion Using Scattered Light from a Laser Guide Star," Nature 353, 144 (1991).

19. R.L. Ulich and J.D.G. Rather, "Innovative Approach to Next Generation Telescope 
Design," Proc. 4th Meeting on Advanced Technology Optical Telescopes, Feb. 1216, 1990, Tucson, AZ, SPIE Volume 1236, pp. 985-995, 1990.

20. R.K. Jain and G.A. Landis, "InP Solar Cells for Laser Power Beaming Applications," Paper 929121, Proc. 27th Intersociety Energy Conversion Engineering Conference, San Diego, CA, August 1992.

21. G.A. Landis, H.E. Eppich and M. Kaliski, unpublished (1992).

22. M.B. Spitzer, J.E. Dingle, R.P. Gale, P. Zavracky, M. Boden and D.H. Doyle, "GaAs Concentrator Solar Cells With Highly Stable Metallization," Proc. 20th IEEE Photovoltaic Specialists Conf., Vol. 2, Las Vegas, NV, Sept. 1988, pp. 930-933.

23. P.R. Younger, G.A. Landis and R.G. Tobin, "Integral Glass Covering of Spacecraft Solar Cells by Electrostatic Bonding," Proc. 14th IEEE Photovoltaic Specialists Conf., San Diego, CA, 1980, pp. 1240-1245.

24. F.M. Curran, G.L. Bennett, R.H. Frisbee, J.C. Sercel, and M.R. LaPointe, "An Overview of the NASA Advanced Propulsion Concepts Program," Paper AIAA-923216, 28th AIAA/SAE/ASME/ASEE Joint Propulsion Conference, Nashville TN, July 6-8 1992.

25. G. Woodcock and D. Eder, Boeing Civil Space Systems, private communication (June 1992). (Much of this work is presented in reference 27.)

26. T.N. Edelbaum, "Propulsion Requirements for Controllable Satellites," ARS Journal Vol. 31, Aug. 1961, p. 1079-1089.

27. E.E. Montgomery, ed., Proceedings of the SELENE FY 91 Program Results and FY92 Program Kickoff, Marshall Space Flight Center, AL, Dec. 10-11, 1991. 
Table 1. Mass breakdown of Laser Electric Propulsion Vehicle $(500 \mathrm{~km}$ starting orbit).

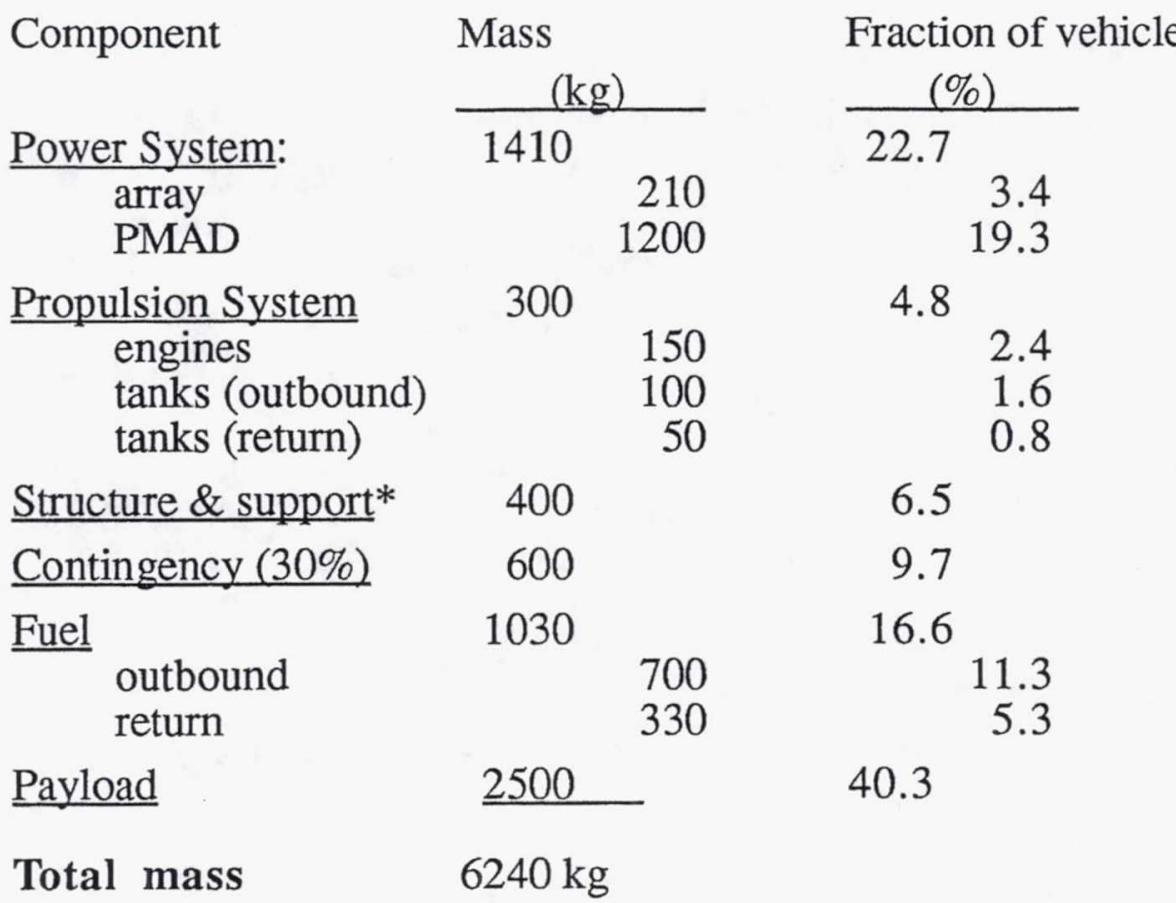

*Includes guidance, control and navigation.

Table 2. Specific mass $(\mathrm{kg} / \mathrm{kW})$ for power and propulsion system components of laser and solar electric propulsion orbital transfer vehicles.

$\underline{\text { Subsystem }}$

Advanced thruster and power processing unit Photovoltaic array

Power Management and Distribution plus TCS

Total power and propulsion specific mass

\begin{tabular}{cc}
\multicolumn{2}{c}{ Specific } \\
$\begin{array}{c}\text { Laser } \\
\text { OTV } \\
(\mathrm{kg} / \mathrm{kWe})\end{array}$ & $\begin{array}{c}\text { Solar } \\
\text { OTV } \\
(\mathrm{kg} / \mathrm{kWe})\end{array}$ \\
\hline 0.5 & 0.5 \\
0.7 & 9.6 \\
$\underline{1.8}$ & $\underline{1.8}$ \\
3.0 & 11.9
\end{tabular}

Mass and performance assumptions common to both vehicles:

All support systems (structures, thermal, communications, etc.) modelled after Mariner mark II Bus Advanced thruster performance: $\mathrm{I}_{\mathrm{sp}}=5000 \mathrm{sec}$, Efficiency $=50 \%$, tankage factor $=0.12$

Mission: $2500 \mathrm{~kg}$ payload to geosynchronous Earth orbit

Solar: GaAs radiation shielding 500 microns front, 300 microns rear

Laser:continuous annealing of radiation damage

BOL laser PV array has power output per unit area ten times higher than solar array. 
Table 3. Typical performance range of ion, arcjet, and MPD thrusters compared with assumed electrodeless pulsed inductive thruster.

\begin{tabular}{|c|c|c|c|c|c|}
\hline Thruster & $\begin{array}{l}\text { Thruster } \\
\text { Efficiency }\end{array}$ & $\begin{array}{l}\text { Specific } \\
\text { Impulse } \\
\text { (sec) }\end{array}$ & $\begin{array}{l}\text { Thruster \&PPU } \\
\text { specific mass } \\
\text { (kg/kWe) }\end{array}$ & $\begin{array}{l}\text { Thrust } \\
\text { (N) }\end{array}$ & $\begin{array}{l}\text { Lifetime } \\
(\mathrm{sec})\end{array}$ \\
\hline Ion Thruster & $0.6-0.80$ & $3000-10000$ & $4-8$ & $0.1-7$ & $\sim 4 \cdot 10^{7}$ \\
\hline Arcjet & $0.3-0.5$ & $400-1500$ & $3-8$ & $0.1-7$ & $\sim 4 \cdot 10^{6}$ \\
\hline MPD Thruster & $0.1-0.5$ & $1000-10000$ & $1-8$ & $0.6-20$ & $\sim 2 \cdot 10^{7}$ \\
\hline $\begin{array}{l}\text { Advanced Pulsed } \\
\text { Inductive Thruster }\end{array}$ & 0.5 & $5000-10000$ & 0.5 & $1.0-20$ & $\sim 1 \cdot 10^{8}$ \\
\hline
\end{tabular}




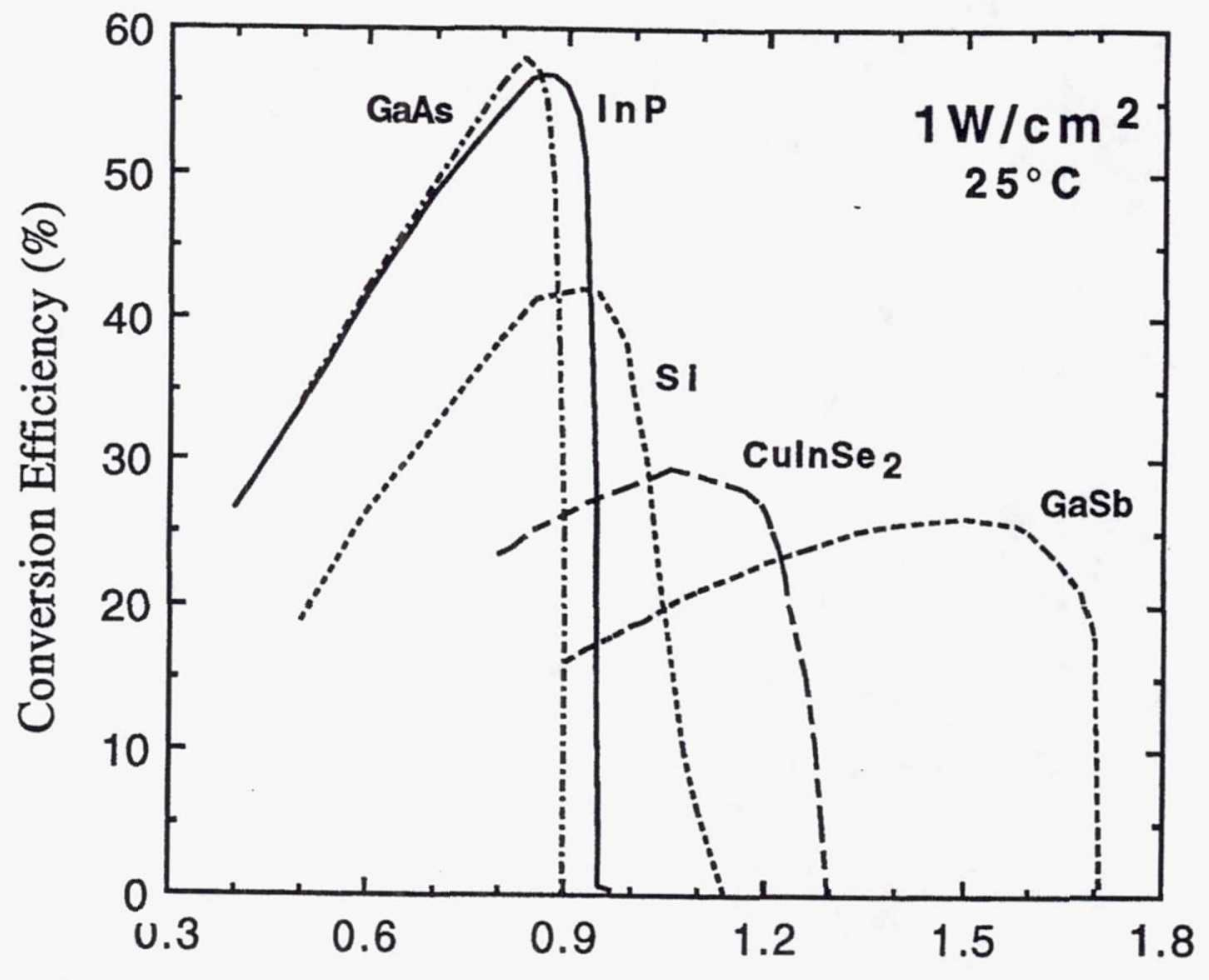

Figure 1.-Efficiency of photovoltaic conversion as a function of wavelength $\left(25^{\circ} \mathrm{C}, 1 \mathrm{~W} / \mathrm{cm}^{2}\right)$ for several types of solar cell. [Data on all cells except InP from reference [4]; InP efficiencies are calculated results from reference [20]. 


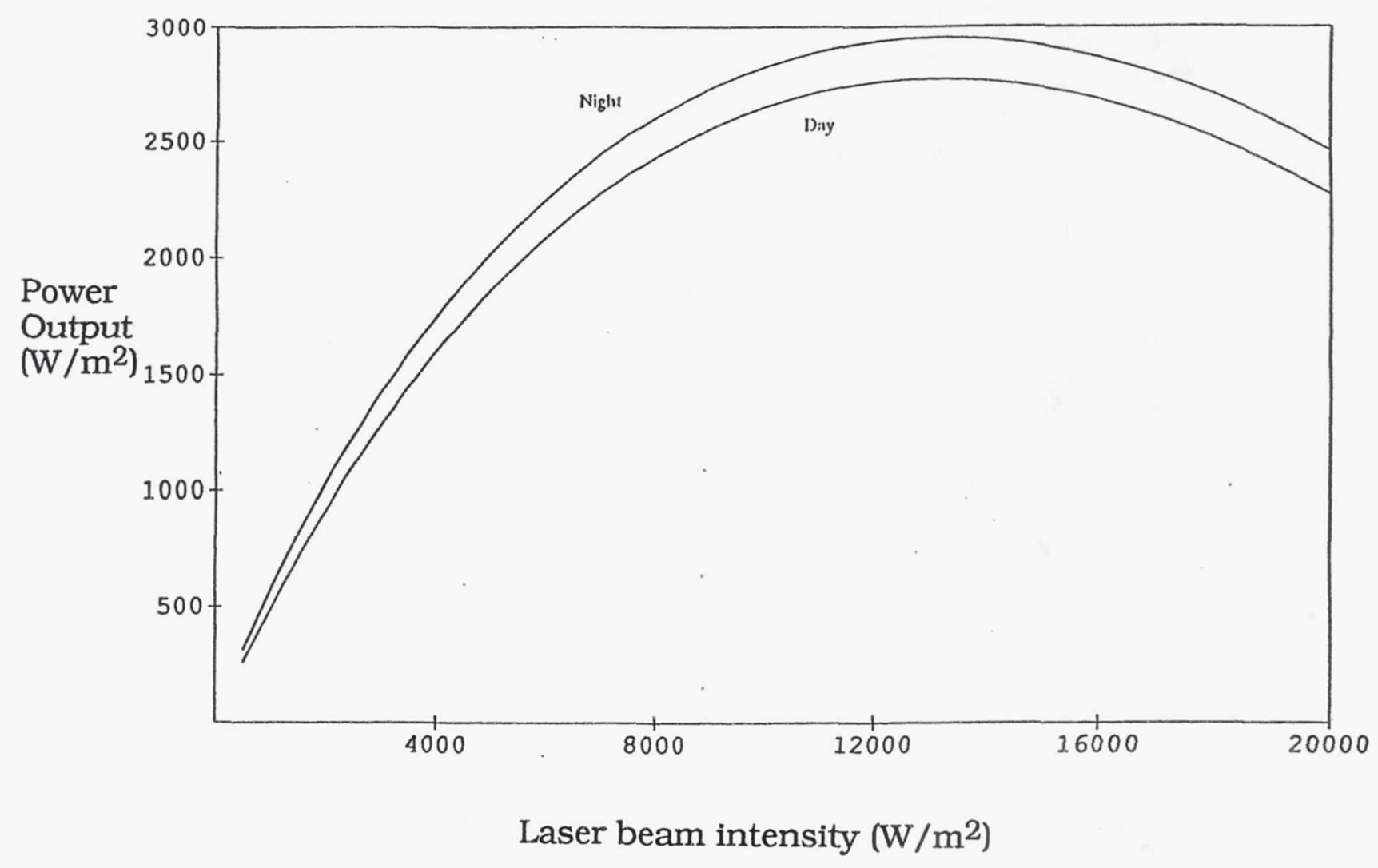

Figure 2.-Power output from an example GaAs photovoltaic array as a function of laser intensity in. The "day" case represents worst-case conditions, with solar heating on the back side of the array. 


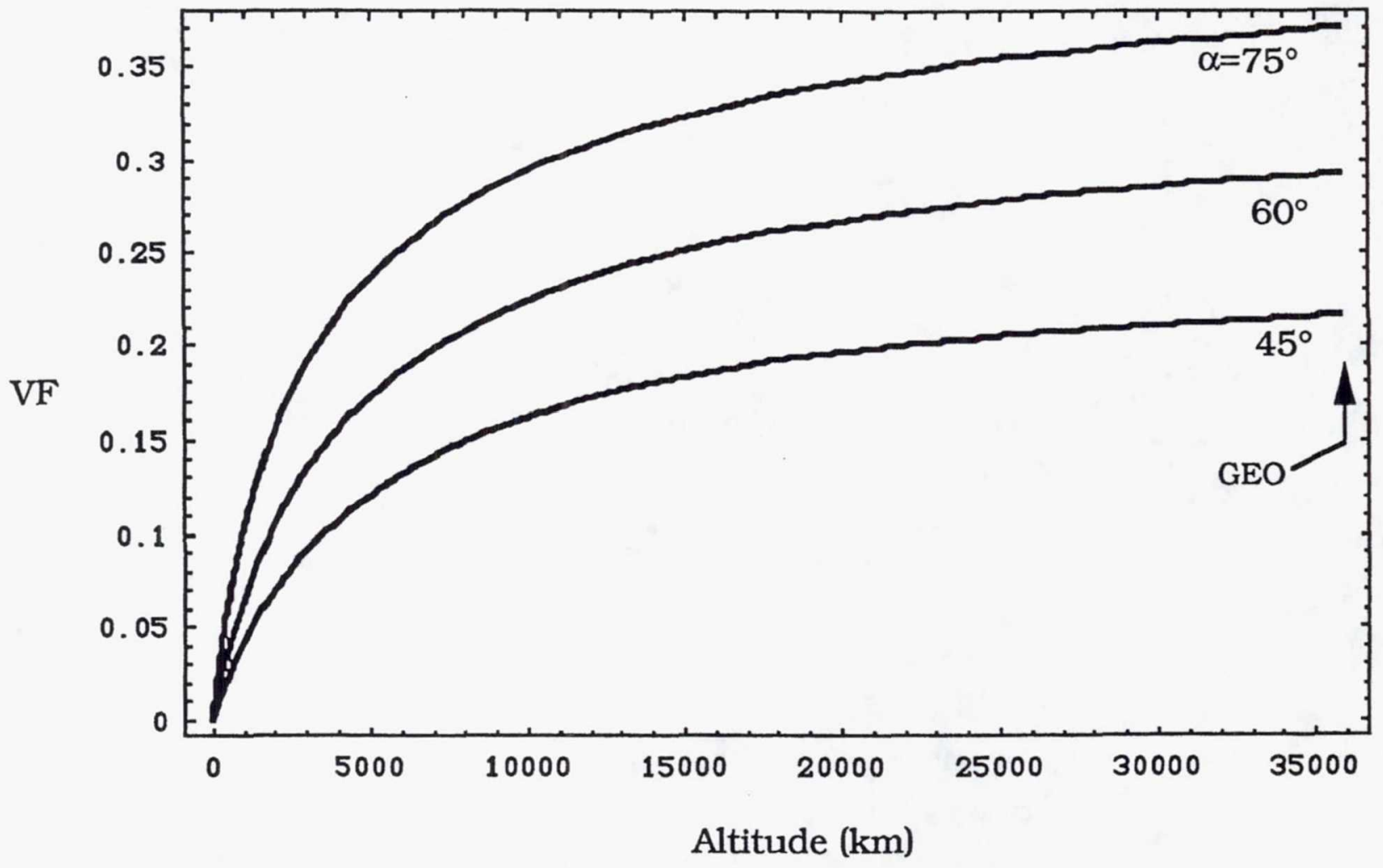

Figure 3.-View Factor to Low Earth Orbit (best case; from equatorial ground site to equatorial orbit). 


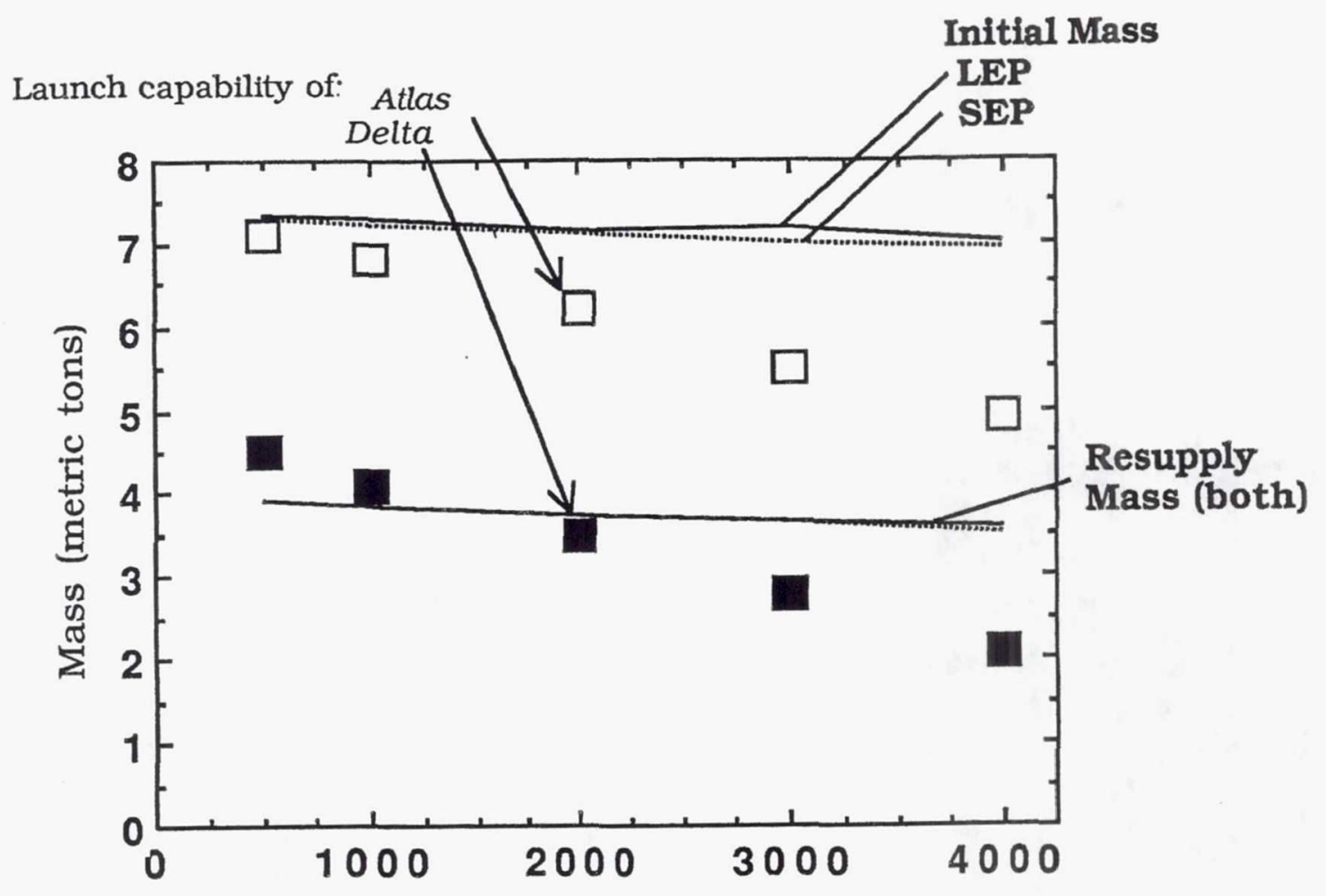

Figure 4.-Initial Mass in Low Earth orbit (IMLEO) for solar- and laser-electric propelled orbital transfer vehicles, as a function of initial LEO altitude. Both the first flight and subsequent ("resupply") missions bringing $2500 \mathrm{~kg}$ satellite to GEO are shown. For comparison, the launch capability of the Atlas 2AS and the Delta 7920 boosters are also shown. 


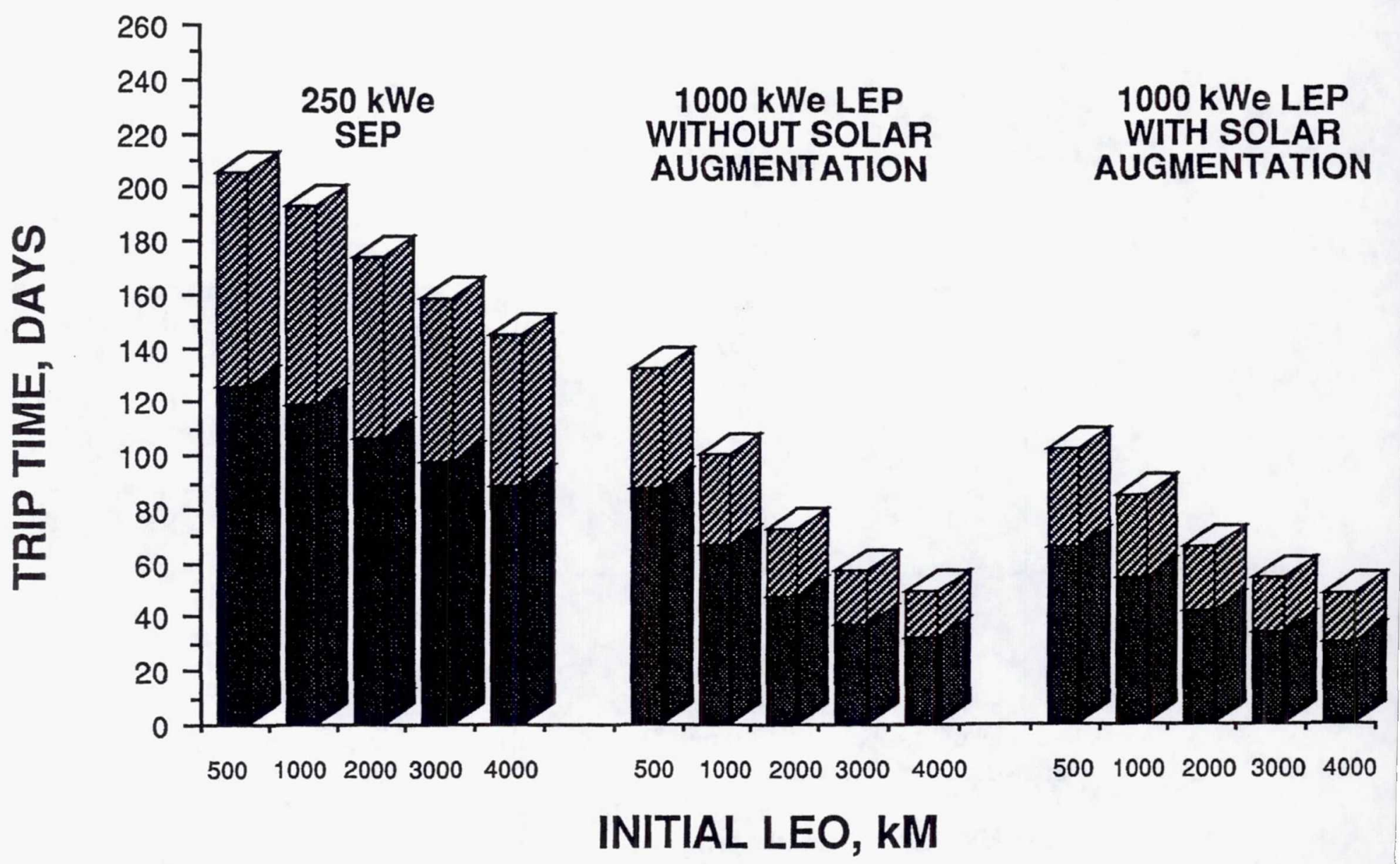

DUTBOUND

WIA RETURN

Figure 5.-Outbound and Return travel times for orbital transfer vehicles between LEO and GEO. 
Public reporting burden for this collection of information is estimated to average 1 hour per response, including the time for reviewing instructions, searching existing data sources, gathering and maintaining the data needed, and completing and reviewing the collection of information. Send comments regarding this burden estimate or any other aspect of this
collection of information, including suggestions for reducing this burden, to Washington Headquarters Services, Directorate for information Operations and Peports, 1215 Jefferson Davis Highway, Suite 1204, Arlington, VA 22202-4302, and to the Office of Management and Budget, Paperwork Reduction Project (0704-0188), Washington, DC 20503.

\begin{tabular}{|l|c|c|}
\hline 1. AGENCY USE ONLY (Leave blank) & $\begin{array}{c}\text { 2. REPORT DATE } \\
\text { July } 1993\end{array}$ & $\begin{array}{r}\text { 3. REPORT TYPE AND DATES COVERED } \\
\text { Technical Memorandum }\end{array}$ \\
\hline
\end{tabular}

4. TITLE AND SUBTITLE

Space Transfer With Ground-Based Laser/Electric Propulsion

6. AUTHOR(S)

Geoffrey A. Landis, Mark Stavnes, Steve Oleson, and John Bozek
7. PERFORMING ORGANIZATION NAME(S) AND ADDRESS(ES)

National Aeronautics and Space Administration

Lewis Research Center

Cleveland, Ohio 44135-3191

9. SPONSORING/MONITORING AGENCY NAMES(S) AND ADDRESS(ES)

National Aeronautics and Space Administration

Washington, D.C. 20546-0001
5. FUNDING NUMBERS

WU-506-46-11

8. PERFORMING ORGANIZATION REPORT NUMBER

E-7663

10. SPONSORING/MONITORING AGENCY REPORT NUMBER

NASA TM-106060

AIAA-92-3213

11. SUPPLEMENTARY NOTES

Prepared for the 28th Joint Propulsion Conference and Exhibit cosponsored by the AIAA, SAE, ASME, and ASEE, Monterey, California, June 28-30, 1993. Geoffrey A. Landis, Mark Staxnes, and Steve Oleson, Sverdrup Technology, Inc., Lewis Research Center Group, 2001 Aerospace Parkway, Brook Park, Ohio 44142. John Bozek, NASA Lewis Research Center. Responsible person, Geoffrey A. Landis, (216) 433-2238.

12a. DISTRIBUTION/AVAILABILITY STATEMENT

12b. DISTRIBUTION CODE

Unclassified - Unlimited

Subject Category 20

13. ABSTRACT (Maximum 200 words)

A new method of providing power to space vehicles consists of using ground-based lasers to beam power to photovoltaic receivers in space. This can be used as a power source for electrically propelled orbital transfer vehicles.

\section{SUBJECT TERMS}

Orbital transfer; Electric propulsion; Laser applications

17. SECURITY CLASSIFICATION
OF REPORT
Unclassified

NSN 7540-01-280-5500

18. SECURITY CLASSIFICATION
OF THIS PAGE
Unclassified

Unclassified

\begin{tabular}{|c|c|}
\hline & $\begin{array}{l}\text { 15. NUMBER OF PAGES } \\
20\end{array}$ \\
\hline & $\begin{array}{r}\text { 16. PRICE CODE } \\
\text { AO3 }\end{array}$ \\
\hline $\begin{array}{l}\text { 19. SECURITY CLASSIFICATION } \\
\text { OF ABSTRACT } \\
\text { Unclassified }\end{array}$ & 20. LIMITATION OF ABSTRACT \\
\hline
\end{tabular}

Standard Form 298 (Rev. 2-89)

Prescribed by ANSI Std. Z39-18 298-102 